\title{
Reducing open access publication costs for biomedical researchers in the U.S.A.
}

\author{
Daniel A. Gorelick ${ }^{1, *}$ and $\mathrm{Ye} \mathrm{Li}^{2, * *}$
}

Edited by Lisa D. Cervia and Grant A. Knappe

\section{HIGHLIGHTS}

- Biomedical publishing is adopting an open access model, where peer-reviewed manuscripts are free to read, but authors pay a fee to the journal to publish their manuscript

- Funding agencies often pay publication fees on behalf of scientists

- Publication fees are rising much faster than inflation, putting a burden on scientists and funding agencies to adopt open access policies that reduce costs to authors

Open Access (OA) publishing is a critical route for biomedical researchers to broadly disseminate their research results and comply with policies from funding agencies. A popular business model for OA publishing requires scientists to pay an article processing charge (APC). In the last two decades, APCs have risen well beyond inflation, posing a burden to scientists and funding agencies that often pay APCs on behalf of scientists. There are no policies in place that address the rising costs of APCs. Here, we examined the history of $O A$ in biomedical research and analyzed the benefits and limitations of different OA policies and their effects on APCs.

B iomedical researchers disseminate the results of their research by publishing results in peer-reviewed journals. Historically, publication operated under a subscription model. Scientists would submit manuscripts to journals, journal publishers would organize peer-review and decide whether or not to publish the manuscript. Once the manuscript was published, readers would pay publishers to read the published articles. Journal subscription fees were typically paid for by universities or other research organizations on behalf of their faculty. The subscription model restricts access of scientific results to those that can afford to pay to read them. A single university cannot afford to subscribe to every journal.

\footnotetext{
${ }^{1}$ Department of Molecular and Cellular Biology, Center for Precision Environmental Health, Baylor College of Medicine, Houston, TX

${ }^{2}$ MIT Libraries, Massachusetts Institute of Technology, Cambridge, MA

*Email: Daniel.Gorelick@bcm.edu

**Email: yel@mit.edu
}

The authors declare no conflict of interest.

(C) 2021 The Author(s)
Additionally, the ability to distribute and read journal articles digitally, on the World Wide Web, made it easier for readers to access journal articles. In response, biomedical research, among other disciplines, is adopting an open access (OA) model [1], where journal articles are free to read online.

When the peer-reviewed journal articles are free to read, innovative business models are needed to pay for the cost of publishing, in place of the subscription model. One popular model is to require that authors pay an article processing charge (APC) to the journal's publisher upon acceptance of a scientific manuscript for publication. Currently, the APCs are rising and outpacing inflation. Between 2012 and 2016, a study of 10 leading universities in the United Kingdom found that the average APC paid by or on behalf of scientists increased $16 \%$, while the consumer price index, a marker of inflation, increased 5\% [2]. A meta-analysis of variations in APC trends from 2011 to 2021 also demonstrated the increases of average APCs are well above the inflation rate for most of the journal categories examined [3]. For example, the average APC change is $186 \%$ in comparison with inflation for the journals with high Impact Factors in the Journal Citation Report (JCR) [4] and indexed by the Directory of Open Access Journals (DOAJ) [5]. As the number of scientific papers increases annually, and as more scientific papers are published with open access rather than on a subscription basis, this creates a cycle of positive reinforcement that could drive APCs higher. In this policy paper, we discuss ways to reduce open access publication costs for biomedical researchers in the U.S.A. We recognize that issues of open access and APCs affect scientists of all disciplines all over the world, and there may not be a single policy optimal for all disciplines in all locations. In the United States, the government spends more money funding biomedical research than funding physics, chemistry and other disciplines [6] Thus, we restrict our analysis to biomedical research, though some of the policy options explored here may be relevant for other disciplines.

\section{A brief history of open access in biomedical research}

In 1996, the Journal of Clinical Investigation became the first prominent biomedical journal to be completely free to read online. Instead of libraries paying a subscription fee, authors paid an article processing charge to have their manuscripts published in the Journal of Clinical Investigation [7]. In 
the 2000s, more journals began publishing peer-reviewed articles online, making it easier for open access to thrive. In 2000, the National Institutes of Health (NIH) established PubMed Central (PMC), a free, online, full-text archive of biomedical and life sciences journal literature [8]. Since 2008, the United States Government required that peer-reviewed manuscripts produced by investigators funded by the $\mathrm{NIH}$ be deposited in PubMed Central no later than 12 months after the official date of publication in a peer-reviewed journal [9]. The 12 month embargo was a compromise between publishers, concerned about losing revenue if their subscription material was available to read immediately, and scientists, funders, and the general public, who wanted results free to read immediately [10]. The 12 month embargo only partially solved the open access problem. Scientists who can't pay journal subscription costs are still at a competitive disadvantage compared to colleagues that can read published results immediately and begin follow-up studies. When we discuss Open Access publications in this article, we focus on peer-reviewed manuscripts or published version of records that are free to read immediately upon acceptance to the journal, with no embargo period following publication.

In 2018, a consortium of European funding agencies, cOAlition S, created Plan $\mathrm{S}$, an initiative to promote full and immediate Open Access to research publications [11]. Funding agencies that are cOAlition $S$ members, such as Wellcome Trust, require their grantees to publish their results in "Open Access Journals, on Open Access Platforms, or made immediately available through Open Access Repositories without embargo" and may provide funds for their grantees to publish OA. Plan S, however, does not directly address open access publication costs. Plan $S$ does not determine who will pay APCs and encourages, but does not require, publishers to be transparent about their costs to define a fair market value for APCs [12]. Moreover, none of the federal funding agencies in the U.S. participates in cOAlition $\mathrm{S}$, in part because the White House Office of Science and Technology expressed concerns about telling researchers where to publish (cOAlition $S$ grantees cannot publish in journals that lack an open access option as of January 1, 2021) [13].

\section{Article processing charges (APC)}

As a popular model for OA, APC can cover the publishing costs and solve issues regarding access. But there are no regulations that limit the APC amount. For example, publishing in an influential journal is seen as a professional benefit, one that scientists think can lead to promotions and increase their chances of receiving grant funding (money provided by the government or private foundations to pay for biomedical research). The demand to publish in influential journals is high, therefore such journals can charge higher APCs, as has occurred in the last decade [3].

How do scientists pay APCs? Some universities provide scientists with funds for this purpose, although they often only partially cover the full APCs for biomedical journal articles [14]. More commonly in Biomedical fields, funding agencies, such as the National Institutes of Health, enable authors to use grant money to pay APCs. However, funding agencies and universities often do not have an official limit on the amount of money that can be used to pay publication charges. When the funder is a government organization, such as the U.S. National Institutes of Health $(\mathrm{NIH})$, then this invites scrutiny of whether paying high APCs supports the funding agency's mission.

\section{Current OA publishing policies}

Open access publication policies for biomedical journals are generally driven by research funding agencies. Papers containing research funded by the U.S. National Institutes of Health must be free to read no later than one year following publication [9]. Papers containing research funded by the Howard Hughes Medical Institute (effective January 1, 2022), the Bill \& Melinda Gates Foundation, Wellcome Trust, and the World Health Organization must be free to read immediately upon publication $[15,16]$. Many funding agencies in the European Union and United Kingdom require that researchers make their published manuscripts free to read immediately [17].

Journals offer a mix of open access and subscription options, depending on the journal. Some subscription-based journals offer an open access option for individual manuscripts, which are often referred to as hybrid journals. Other journals are entirely open access, or entirely subscription-based. The hybrid journals can result in confusion around whether a publisher is "double dipping" - charging authors APCs while charging institutions for subscriptions fees. Some medical journals do not offer authors OA options when their research is funded by agencies that do not mandate OA publishing.

Journal publishers typically follow government regulations or funder mandates regarding open access. For example, for research funded by the $\mathrm{NIH}$, subscription-based journals will make manuscripts free to read one year after publication, by depositing the peer-reviewed manuscripts in PubMed Central. In some cases, subscription-based journals make published articles freely available after six months rather than the one year embargo period mandated by the $\mathrm{NIH}$, for example journals published by the American Medical Association and the U.S. National Academy of Sciences [18].

Journals can be published by for-profit companies (e.g., Elsevier, SpringerNature) or non-profit (or not-for-profit) organizations including scientific societies (e.g., Company of Biologists, American Association for the Advancement of Science). Sometimes a non-profit scientific society will contract a for-profit publishing company to publish their journal (e.g., Developmental Biology, the official journal of the non-profit Society for Developmental Biology, is published by Elsevier). In every case, journals have an incentive to maximize revenue, to either increase shareholder profits in the case of for-profit publishing companies, or to increase the ability to provide services to members and benefit the public good, in the case of scientific societies and other 
non-profit organizations (two examples of exceptions to this rule of maximizing revenue, the journals Environmental Health Perspectives and Quantitative Science Studies, are discussed later). For profit publishers may choose to use profits to benefit the scientific community and the public good (at the expense of returning profits to shareholders), but they are under no legal obligation to do so. During the process of transitioning from the traditional subscription model to the OA publishing model, maximizing revenue means charging a higher APC, publishing more articles, or both.

The more prestigious or influential the journal, the higher the APC $[19,20]$. For example, SpringerNature charges $\$ 11,500$ (€9500) to publish OA in Nature (Article Influence Score 22), $\$ 5,380$ to publish in Nature Communications (Article Influence Score 5.5) and $\$ 1,870$ to publish in Scientific Reports (Article Influence Score 1.9) [21]. No matter how influence is measured, whether using Impact Factor, article influence score, or other metric such as citability, there is a positive correlation between APC and journal influence [22]. The article influence score (AIS) measures the average influence of each of a journal's articles over the first five years after publication [20]. AIS is similar to the journal impact factor but corrects for self-citations. AIS is normalized so that the mean article in the Clarivate Journal Citation Reports (JCR) database has an AIS of 1.00. In 2019, the average article in Nature Communications had 5.5 times the influence of the average article in the JCR. Scientists use journal impact factors and to assign a relative measure of influence to biomedical journals (the higher the impact factor, the more influential and prestigious the journal), but impact factor and AIS are not absolute measures and should be used with caution [23]. APCs positively correlate with journal influence among journals from the same publisher (Fig. 1).

There are no regulations that limit APCs, although some funding agencies have set a maximum on the APCs they are willing to pay (see Policy Type 3, below). Scientists value prestige as professional currency and pay publication or subscription costs using someone else's money, typically money provided by the funding agency supporting the research project or the research institution where the scientists work. Scientists from lower income countries or underprivileged institutions are left with little or no options to pay APCs. Some publishers may selectively provide APC waivers or discount for low- and middle-income countries [24] but they may not be as consistent and transparent as needed [25]. In addition, a recent study found that global health researchers in low- and middle-income countries (LMIC) cite non-OA articles less than researchers from upper-income countries [26]. This suggests that researchers from LMIC are not reading and citing non-OA manuscripts as frequently as OA manuscripts, likely because of the cost to read non-OA manuscripts.

The publication polices of funding agencies, research institutions, governments, scientific societies and publishers are related and influence each other. Here, we focus on policies of funding agencies, since they have the broadest and most fundamental impact. If funding agencies require open access, then most scientists must comply. Individual research institutions may also have their own OA policies, but these policies often provide opt-out options for researchers and thus are not enforced $100 \%$ in practice $[27,28]$. In addition, although we are not focusing on open data policies in this article, they are important components of open science policies along with the OA publishing policies.

\section{Policy Type 0: Maintain the status quo but eliminate the open access embargo}

In this model, NIH-funded publications would be deposited in PubMed Central immediately following publication. People could read peer-reviewed manuscripts for free immediately following publication without waiting for a 12 month embargo to elapse.

Advantages: This policy would make the United States compliant with Plan S. All NIH-funded research would be free to read immediately to anybody in the world.

Disadvantages: This policy does not address the costs of APCs to scientists. Journal publishers would be free to set APCs as they wish, with no maximums, as is the case currently. Scientists would need to find ways of paying the APCs, using either grant money, institutional funds or personal funds. Additionally, changing the NIH public access policy would likely require action by the U.S. Congress.

\section{Policy Type 1: Funding agency pays open access costs directly}

In this model, open access journals are directly supported by funding agencies such that there is no charge to funded authors to publish and no charge to read published articles. Funding agencies might publish a journal themselves or pay a publishing company so that grantees are charged nothing to publish. Several existing journals demonstrate the feasibility of this model. Environmental Health Perspectives is the most influential journal in the field of toxicology and environmental health sciences. Published by the National Institute of Environmental Health Sciences at the $\mathrm{NIH}$, it charges authors no publication fees and is free to read [29, 30]. Environmental Health Perspectives has been published using this model since 2004 and has no plans to change their publishing model.

Wellcome Trust and the Bill \& Melinda Gates Foundation pay a for-profit publisher, F1000 Research Ltd., to publish Wellcome Open Research and Gates Open Research journals, respectively $[31,32]$. These journals are free to read and charge authors no article publication costs (CC BY license) provided the author's research is funded by the Wellcome Trust or the Gates Foundation. In contrast to Environmental Health Perspectives, these journals are newer and so their reputation and influence in the biomedical sciences is untested.

Advantages: This is the least expensive business model for scientists because scientists would not pay APCs. This model currently works at a small scale for funders with steady financial resources, as evidenced by the journals discussed 


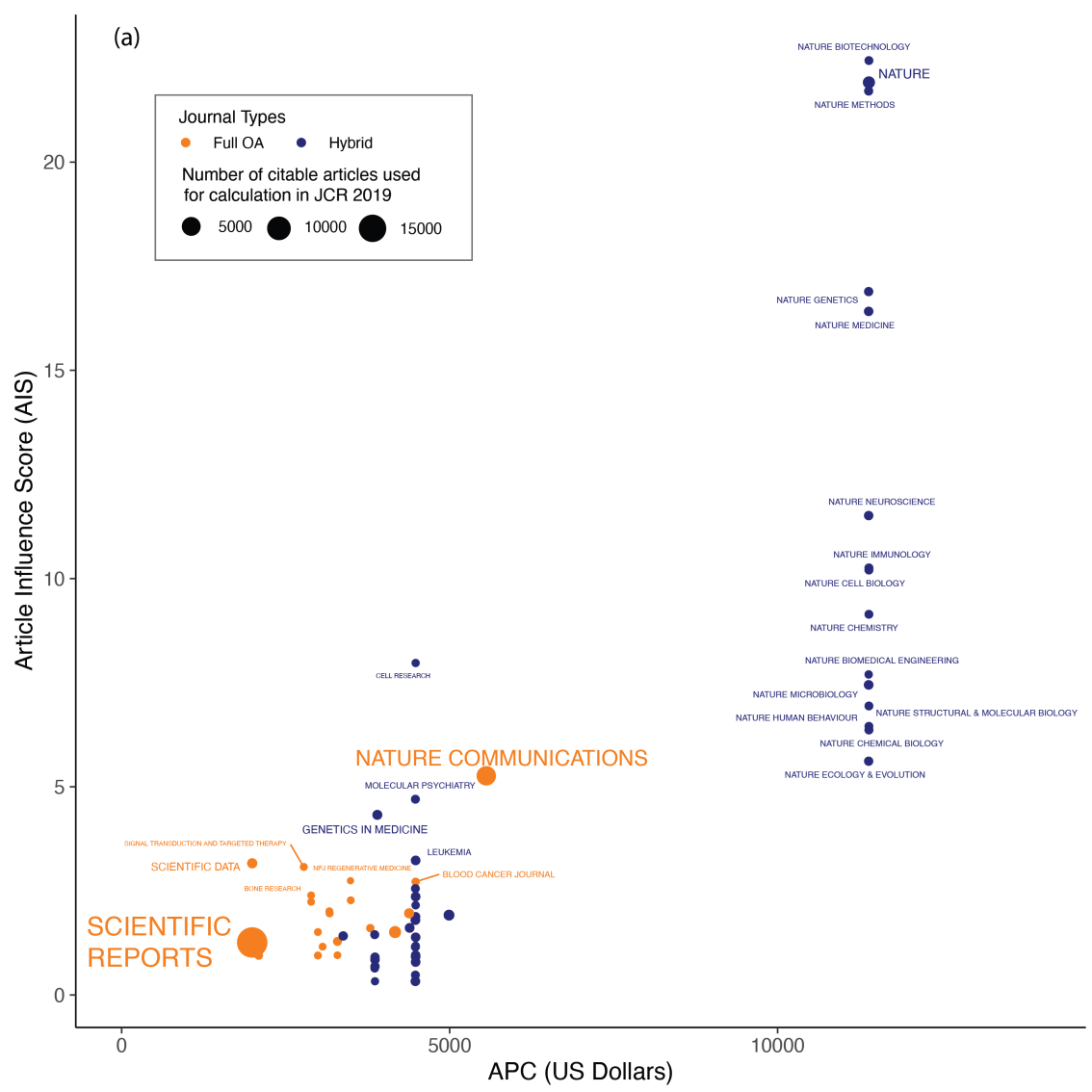

(b)

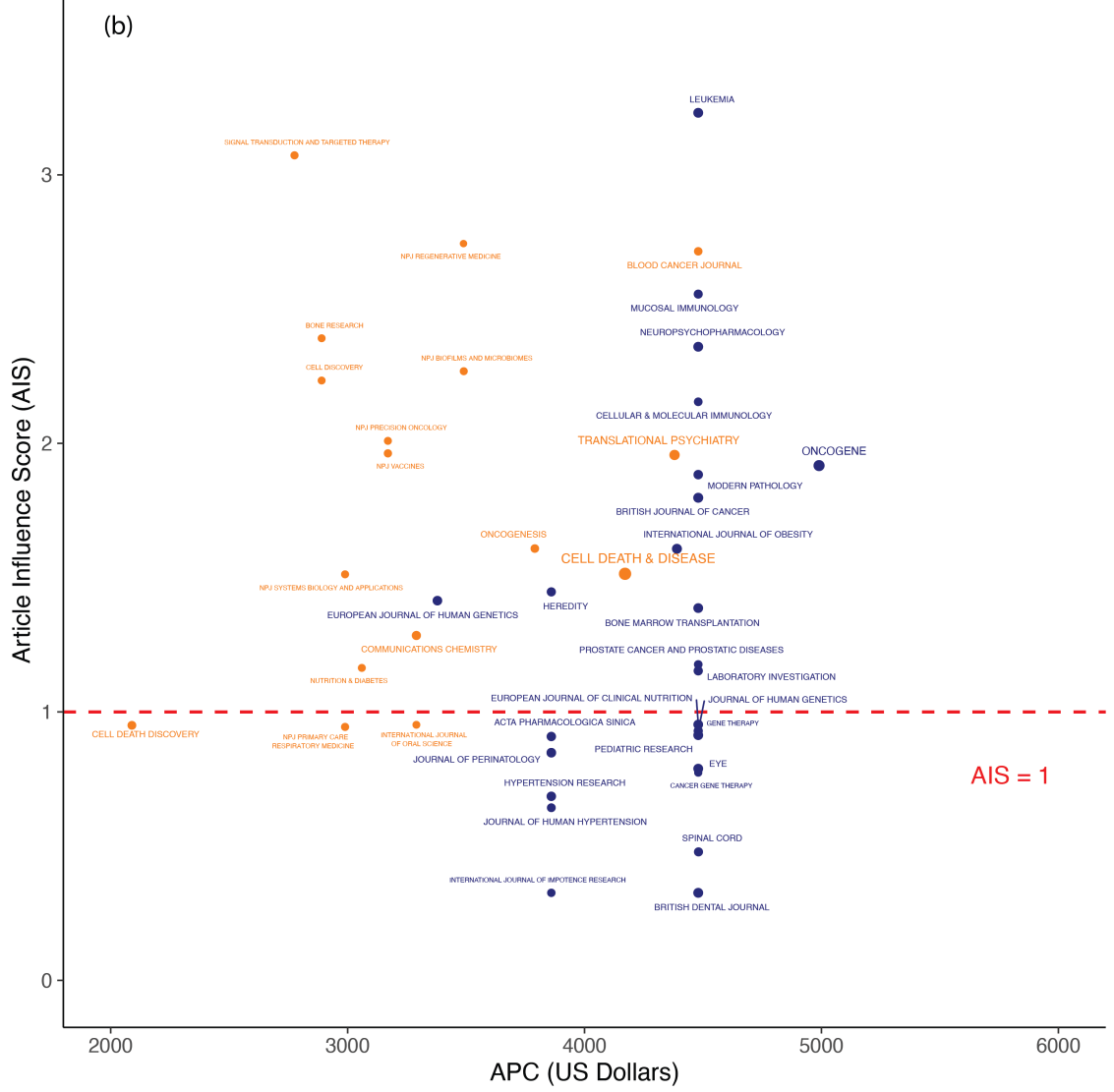


Figure 1: Article Processing Charges (APC) and Article Influence Scores (AIS) of biomedical journals published by SpringerNature under their Nature Portfolio. (a) shows all biomedical journals, (b) focuses on journals with APC between $\$ 2000$ and $\$ 6000$ and AIS less than 3.5. AIS measures the average influence of each of a journal's articles over the first five years after publication, where AIS > 1 has above average influence and AIS $<1$ has below average influence. A journal with an AIS of three means the average article in that journal had three times the influence of the average article in the Clarivate InCites Journal Citation Reports (JCR). APC data were retrieved from https://www. springernature.com/gp/open-research/journals-books/journals on March 4, 2021. The journal impact data including AIS for 2019 were retrieved from JCR 2019 on March 4, 2021.

above. This model would be straightforward to execute, requiring changes to internal $\mathrm{NIH}$ policy but not approval by the U.S. Congress.

Disadvantages: Can this model be scaled up to accommodate the millions of peer-reviewed biomedical research articles published annually [33]? If scaled up, will it limit the publishing options for those researchers who are not funded by these funding agencies? If a funding agency pays for research and supervises publication of the same work, then there is the potential for conflicts of interest to arise. It would be important to keep journals scientifically and editorially independent from funding agencies. Note that Environmental Health Perspectives demonstrates that it is possible for the U.S. government to publish a peer-reviewed scientific journal that is editorially and scientifically independent from the National Institutes of Health.

\section{Policy Type 2: Funding agencies mandate preprint publications}

In this model, funding agencies would require grantees to post manuscripts as preprints on a server like bioRxiv or medRxiv [34]. Preprints are free to post and free to read but are not peer-reviewed. Following posting of a preprint, scientists are free to submit their manuscript for peer-review and publication in any journal, whether subscription or open access.

Advantages: This policy could be implemented rapidly, at little or no cost to funding agencies or research scientists. Results would be free to read immediately.

Disadvantages: The sudden and increased emphasis on preprints would require biomedical researchers to read and comment on preprints, a new ecosystem for biomedical research. It is an empirical question whether this preprint ecosystem will flourish for biomedical research as it has for physics. While preprints are standard in physics, physicists still publish in peer-reviewed journals following preprint submission. Comparing publication approaches in physics and biomedical research is confounded by the differences in the size of each field. The physics preprint server arXiv receives on average 16,000 manuscripts per month [35]. In contrast, PubMed listed approximately 2.5 million peer-reviewed papers per month in 2020 (for a total of 30.4 million) [36], while the biomedical preprint server bioRxiv received about 3300 manuscripts per month (for a total of 40,022).

Additionally, this plan does not address article publication charges for open access journals. Once scientists deposit manuscripts on preprint servers, they may still publish manuscripts in peer-reviewed journals. The desire to publish in high impact journals, and to pay the associated APCs, may not be diminished by the number of preprints. If scientists rely on preprint servers only, an effective peer-review mechanism of preprints will need to be adopted broadly and also allow simple differentiation between peer-reviewed and non peer-reviewed manuscripts. This differentiation is particularly important for biomedical research due to public health implications. It would be disastrous to confuse the public with potential misinformation that would have been corrected by peer-review.

\section{Policy Type 3: Funding agencies cap payments of APCs for grantees}

In the current system, many grantees use funder's money to pay APCs. Funding agencies could set a standard or universal maximum APC in collaboration with publishers. If enough funding agencies and publishers work together to negotiate a maximum APC, then this negotiated APC could drive the adoption of a standard cost of publication in most journals. To achieve such collaborations, certain levels of transparencies in the true cost of publishing and willingness to build a sustainable ecosystem together are essential. There is precedent for funding agencies setting a universal cost standard on scientific goods and services. The NIH set a minimum salary for postdoctoral fellows funded by F32 grants [37]. This minimum is widely followed, even at universities in the U.S. where the head of the laboratory pays postdocs using non-NIH funds. Similarly, the NIH sets a maximum cap on annual salaries for principle investigators, the professors that lead research grants, which makes it expensive for universities to pay professors an annual salary higher than this cap [37]. Thus, the NIH maximum allowable APC could become a universal maximum APC.

An appropriate monetary cap for APCs is complicated to determine. Since 2014, the Austrian Science Fund (FWF) caps payments for its grantees at $€ 2,500$ per manuscript [38]. It is not known whether APCs have stayed the same or gone down as a result. Globally, open access costs increased since 2014 [3], suggesting that the FWF is too small to impact APCs. What factors should be used to determine an appropriate monetary cap is beyond the scope of this article and will take collaborations among the stakeholders to investigate.

Effective January 2021, the Wellcome Trust will "cover fair and reasonable APCs for articles published in fully OA journals" but does not list a specific dollar amount [39]. Wil the Wellcome Trust allow grantees to pay $\$ 2500$ to publish in the Journal of Biological Chemistry, when it costs $\$ 600$ less to publish in Scientific Reports? Both journals have similar subject matter scopes, article influence scores and impact factors. 
Converting an existing subscription-based or hybrid journal to a completely open access journal could be expensive [40]. Some argue that these costs should be subsidized by funding agencies or governments. Others argue that the market should be allowed to find a solution to a funding agency cap on APCs. In the market approach, for-profit publishers would implement a business model where they are profitable despite a cap on the APC. This approach discourages scientists from advising publishers how to run their business.

There is precedent for the market approach, where an open access journal found a way to remain viable despite a low APC. The Journal of Infometrics is a hybrid OA journal, founded in 2006, published by Elsevier. The editorial board was concerned about high APCs and unhappy with the lack of autonomy afforded by working with Elsevier [41]. In 2019, the editorial board of the Journal of Infometrics resigned and started a new journal, Quantitative Science Studies. The QSS editorial board negotiated with several publishers before choosing MIT Press. QSS has the same scope as the Journal of Infometrics, but the APC is $\$ 800$ compared to $\$ 2000$ [41]. If funding agencies capped APCs, existing journals might find a way to remain profitable, or new journals might arise, a la QSS, to meet the requirement for low APCs.

Advantages: Compliance would be close to $100 \%$, as it would be difficult or impossible for scientists to spend funder's money contrary to the funder's wishes. Lower APCs would benefit all researchers, not just those directly funded by influential funding agencies. We note that a maximum APC could be determined by funding agencies and publishers working together. However, it is also possible that their conflicting interests could necessitate funding agencies acting unilaterally to set a maximum APC. Funding agencies have powerful leverage over their grantees.

Disadvantages: Funding agencies such as the NIH have extensive bureaucracies that will hamper implementation of an APC cap. Additionally, it will be difficult to determine an appropriate dollar amount for an APC cap. Should the $\mathrm{NIH}$ determine an APC cap based on what they are willing to pay, or based on publication costs? The latter requires transparency in the cost of publishing, which does not exist. In 2018, European research institutions formed Plan S, a plan to have all research funded by public grants published in open access journals. Plan S attempted to set APC caps but received criticism on how the cap should be negotiated and maintained. Publishers argued in favor of the highest possible APC, while researchers and university administrators argued that publishers are powerful and will negotiate with funding agencies to increase the APC regularly, as occurs today with subscription costs [42]. Now, instead of an APC cap, Plan S advocates for a Price Transparency Framework where publishers provide voluntary data on how much it costs to publish articles [12]. If the publishing industry can be more transparent regarding the true cost of publishing, it could help funding agencies set a reasonable APC cap. On the other hand, Plan S may not have sufficient power to enforce publisher participation because there are no direct incentives for publishers to reduce the APCs. Funders may need to spend additional resources on enforcement and help publishers, especially smaller society publishers, with the transition.

A funder's cap on APCs could restrict authors' intellectual freedom in where they can publish. For example, if Nature refuses to lower their APC, then funding agencies could prohibit their funded researchers from publishing in Nature. One can argue that since the funding agencies are paying for the research, they have a say in how and where the results are disseminated. On the other hand, this sets up a potential conflict of interest. For example, the $\mathrm{NIH}$ has restrictions on the use of human embryonic stem cells in research projects. It could be damaging for the scientific enterprise if these research restrictions extended to publication restrictions for stem cell research. As discussed in Policy Type 1, it would be important to keep journals scientifically and editorially independent from funding agencies.

Some have argued that the open market encourages scientists to publish in journals that deliver a higher quality of service, such as more rapid peer review. However, a recent study found no significant correlation between average review time and APC [22], suggesting that scientists are not paying higher APCs to receive better service.

\section{Policy Type 4: Funding agencies require both preprint} posting and cap payments for APCs

Manuscripts would be immediately free to read as preprints. Once a preprint is published, scientists could submit the manuscript to any peer-reviewed, open access journal that charges an APC within the funder's limits. A possible outcome is that scientists publish preprints and then submit manuscripts to peer-reviewed subscription-based journals, as this is the cheapest path for authors (subscription-based journals charge low or no fees for authors). Therefore, for this policy to be effective, funding agencies would also need to prohibit non-OA publication and cap APCs.

Advantages: Research results would be free to read immediately, due to preprint requirement. During the conventional, peer-reviewed publication process, funder's money is protected and spent efficiently. Biomedical scientists might rely more heavily on discussing findings as preprints (similar to physics) rather than always waiting for peer review, which could take months.

Disadvantages: Requires substantial changes to funder policy and research community culture, making implementation difficult. As discussed in policy type 2, the emphasis on preprints would require biomedical researchers to read and comment on preprints, a new ecosystem for biomedical research. It's an empirical question whether this preprint ecosystem will flourish for biomedical research.

\section{Policy Type 5: Universities negotiate payments to journals so faculty can publish and read for free}

Subscription-based journals charge a fee to read but low or no additional publication fees. Universities currently pay 
journal subscription fees on behalf of their research scientists. Universities could also pay APC fees on behalf of scientists. As the number of subscription-based journals decline and OA journals become more prevalent, some of a university's budget for subscription fees could transform into covering open access publishing fees. Universities could negotiate APCs with publishers. Universities could apply to funding agencies for money to pay publication charges on behalf of entire faculty [43]. The University of California system and PLOS negotiated an agreement whereby the university will pay some or all of the APC on behalf of its faculty if they publish in a PLOS journal [44]. The University of California more recently enacted a similar but complex deal with Elsevier, where the university will pay $\$ 1000$ towards grant-funded authors' APC (authors are expected to use research funds to cover the balance) [45]. The University of Cambridge signed agreements with many publishers to enable researchers at the university to publish their primary research and review articles in open access journals. If the manuscript's corresponding author is affiliated with the University of Cambridge, then authors will not be charged publication fees. This agreement covers more than 5000 journals published by Springer, Wiley, PLOS and the Company of Biologists, among other publishers [27].

Advantages: An inexpensive business model for biomedical researchers because research scientists would pay reduced or no publication fees. The approach works with the existing publication and biomedical journal ecosystem and few changes are required for implementation.

Disadvantages: This policy will be difficult to scale and could lead to different APCs for different universities. Initially, this policy might be feasible for large universities such as Cambridge, or multiple large universities that operate under a single board of directors, such as the University of California system, but smaller universities and colleges would either be left to fend for themselves and negotiate at a disadvantage compared to large universities, or they would need to form coalitions with other institutions, which would take time. Additionally, negotiations between universities and publishers could favor large and established publishers, who control a larger share of the market. A large publisher, like Elsevier, publishes hundreds of journals and would have substantial leverage in a negotiation to determine APC. In contrast, a smaller publisher, such as a scientific society that publishes less than 10 journals, would have less leverage in a negotiation. This could create publishing disparities where scientists at some universities are unable to publish in some journals. To explore new pricing models, Massachusetts Institute of Technology is negotiating with publishers to have price based on value-added services provided by the publisher, and not based on the number of articles published by affiliated authors multiplied by the APCs [46].

\section{Conclusions}

Long term, the least expensive solution for biomedical researchers is to have funding agencies pay the costs of OA publication by publishing their own journals and/or by directly funding journals that are published by a third party. This way, funding agencies could use their power to negotiate lower APCs, while scientists can publish wherever they like for free or at a lower cost if they are not directly funded for paying APCs. Biomedical researchers, funding agencies and publishers could work together to ensure that open access journals are reputable and not predatory. Predatory journals are those self-serving publications that accept publication fees and disseminate manuscripts without any quality check [47]. In this scenario, funding agencies would pay the cost of publication and create a list of prohibited, predatory journals, so the incentive to publish in predatory for-profit journals would plummet.

One concern is that by lowering APCs, journals will decline in quality. Less revenue or lower profit margin for publishers could increase the number of non-rigorous journals, in which the quality of peer review is low and/or the ability to detect fraud, such as image manipulations, is poor. The existance of prestigious and influential journals that charge relatively low or no APCs argues against this outcome. Journals such as eLife, Environmental Health Perspectives and PLOS Biology, whose APCs are thousands of dollars less than similarly influential journals published by Elsevier and SpringerNature, suggests that journals can charge lower APCs without sacrificing quality.

In the short term, a graded implementation might cushion the blow of a rapid transition. One idea is to start by having funding agencies mandate preprint publications, and subsequently have funding agencies cap APCs. Over time, this would lead to agencies directly funding journals that are free to read and free to publish. If the transition takes several years, this will give universities, funding agencies, scientists and publishers time to prepare and adjust.

Moving from a subscription-based model to a new model where all journals are OA raises difficult questions. How will universities access articles previously published in subscription-based journals? Many of these papers were published before funder requirements that manuscripts be free to read one year following publication. Will universities continue to pay access fees to archived papers in journals that no longer publish using a subscription model? Some existing license agreements may include terms for perpetual access to subscribed content but many do not. If implementing some of the options above, funders and universities may need to use their leverage with publishers to ensure that older publications remain accessible.

What happens to professional journal editors, those scientists that work for publishers and edit manuscripts full time? In the face of reduced APC and reduced revenues, journals will need to decide whether the cost of paying professional editors is worthwhile. In the current publishing ecosystem, most journals do not employ professional editors. The fact that so many journals eschew professional editors suggests that professional editors are not required to publish a successful, influential journal. Currently, at most biomedical 
journals peer-review and editing are performed by scientists for free. This need not change if any of the policies above are implemented. If the quality of peer-review remains high and scientists continue to perform peer review for free, then publishers may find that they can reduce costs by paying editors less (or not paying editors at all).

Finally, these policies will have substantial impact on the publishing industry over all. If funders cap APCs or publish OA journals themselves, profit margins for many publishers will likely decrease. Some journals and/or publishers could go out of business. Other publishers might find a way to reduce costs, make publishing more efficient and remain profitable. Funders could consider providing additional support on a case-by-case basis for vulnerable publishers, such as small non-profit scientific societies, during the transition. Scientists have been contributing their expertise as authors, editors, and peer reviewers, mostly for free, to the publishing ecosystem for more than a century. Publishers, funders and universities should make that ecosystem more equitable and sustainable. Journals like Environmental Health Perspectives and Wellcome Open Research demonstrate that peer-reviewed results can be published at reasonable cost to scientists and funding agencies. Scientists and funding agencies should ask how sustainable it is in the long-term to spend the extra tens of thousands of dollars per article to publish in highly prestigious journals like Nature. Communicating results as inexpensively as possible, while still maintaining rigorous criticism and discussion, will benefit scientists, universities, funding agencies and ultimately every person whose life is improved by discoveries made in biomedical research labs.

\section{Acknowledgements}

We thank Drs. Prachee Avasthi, Peter Rogers and Richard Sever for helpful discussions during the preparation of this manuscript, and Drs. Rachel Arey, Courtney Hodges and Margot Williams for feedback on initial drafts of the manuscript. The idea for this manuscript arose following a spontaneous discussion between D.A.G and Dr. Margaret A Goodell at a department holiday party in 2019. We thank Dr. Goodell for her insights on publication practices at scientific societies. We thank Laura Hanscom for her feedback and insights from the academic library perspective.

\section{Citation}

Gorelick, D. A. \& Li, Y. Reducing open access publication costs for biomedical researchers in the U.S.A. MIT Science Policy Review 2, 90-98 (2021). https://doi.org/10. $38105 /$ spr.4nulqfjf3t.

\section{Open Access}

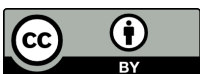

This MIT Science Policy Review article is licensed under a Creative Commons Attribution 4.0 International License, which permits use, sharing, adaptation, distribution and reproduction in any medium or format, as long as you give appropriate credit to the original author(s) and the source, provide a link to the Creative Commons license, and indicate if changes were made. The images or other third party material in this article are included in the article's Creative Commons license, unless indicated otherwise in a credit line to the material. If material is not included in the article's Creative Commons license and your intended use is not permitted by statutory regulation or exceeds the permitted use, you will need to obtain permission directly from the copyright holder. To view a copy of this license, visit http://creativecommons.org/licenses/ by $/ 4.0 /$.

\section{References}

[1] Suber, P. Open Access. The MIT Press Essential Knowledge series (MIT Press, Cambridge, MA, USA, 2012). Online: https: //openaccesseks.mitpress.mit.edu/.

[2] Monitoring the transition to open access: December 2017. Tech. Rep., Universities UK (2017). https: //www.universitiesuk.ac.uk/policy-and-analysis/ reports/Pages/monitoring-transition-openaccess-2017. aspx. Accessed: July, 2021.

[3] Morrison, H., Borges, L., Zhao, X., Kakou, T. L. \& Shanbhoug, A. N. Open access article processing charges 2011 . 2021. Preprint. (2021). Online: http://ruor.uottawa.ca/ handle/10393/42327.

[4] Journal Impact Factor - Journal Citation Reports (2021) Online: https://clarivate.com/webofsciencegroup/ solutions/journal-citation-reports/. Clarivate, Web of Science Group, Accessed: July, 2021.

[5] Directory of Open Access Journals (2021). Online: https:// doaj .org/. Directory of Open Access Journals, Accessed: July, 2021.

[6] Federal Funds for Research and Development: Fiscal Years 2019-20. NSF 21-329, National Center for Science and Engineering Statistics (NCSES),National Science Foundation, Alexandria, VA (2021). Online: https://ncses.nsf.gov/ pubs/nsf21329/. Accessed: July, 2021.

[7] Jackson, S. Free access to scientific publications: contrasting the $\mathrm{JCl}$ approach to Plan S. The Journal of Clinical Investigation 129 440-441 (2020). https: // doi.org/10.1172/JCI126932.

[8] PMC Overview (2021). Online: https://www.ncbi.nlm. nih.gov/pmc/about/intro/. US National Library of Medicine, National Institutes of Health, Accessed: July, 2021.

[9] NIH Public Access Policy Details (2009). Online: https:// publicaccess.nih.gov/policy.htm. National Institute of Health, Accessed: February, 2021.

[10] The Grand Compromise of U.S. Public Access Programs: Going Green (2016). Online: https://www. newswise.com/ articles/the-grand-compromise-of-u-s-publicaccess-programs-going-green. DOE Science News Source, Newswise, Accessed: July, 2021.

[11] About | Plan S and cOAlition S (2021). Online: https: //www.coalition-s.org/about/. cOAliationS, Accessed: July, 2021.

[12] Price and Service Transparency Frameworks (2021). Online: https://www.coalition-s.org/price-and-servicetransparency-frameworks/. Plan S: Making full \& immediate Open Access a reality, Accessed: April, 2021.

[13] An Interview with OSTP Director Kelvin Droegemeier (2019). Online: https://www.aip.org/fyi/2019/interviewostp-director-kelvin-droegemeier. American Institute of Physics, Accessed: July, 2021.

[14] Tananbaum, P. G. North American Campus-Based Open Access Funds: A Five-Year Progress Report. Tech. Rep., SPARC, the Scholarly Publishing and Academic Resources Coalition (2014). https://sparcopen.org/wp-content/uploads / 2016/01/OA-Fund-5-Year-Review.pdf. 
[15] Sherpa Juliet - Browse Funders (2021). Online: https://v2. sherpa.ac.uk/view/funder_list/1.html. JISC Digital Resources, Open Access, Accessed: April, 2021.

[16] Keeley, J. \& Rosen, M. HHMI Announces Open Access Publishing Policy (2020). Online: https://www.hhmi.org/ news/hhmi-announces-open-access-publishingpolicy. Howard Hughes Medical Institute, Accessed: April, 2021.

[17] Organisations endorsing Plan $S$ and working jointly on its implementation (2021). Online: https://www.coalitions.org/organisations/. Plan S: Making full \& immediate Open Access a reality, Accessed: April, 2021.

[18] PMC Journals (2021). Online: https://www.ncbi.nlm.nih. gov/pmc/ journals/. PubMed Central, US National Library of Medicine, National Institutes of Health, Accessed: April, 2021.

[19] West, J. D., Bergstrom, T. \& Bergstrom, C. T. Cost Effectiveness of Open Access Publications. Economic Inquiry 52, 1315-1321 (2014). https://doi.org/10.1111/ecin.12117.

[20] Bergstrom, C. T., West, J. D. \& Wiseman, M. A. The Eigenfactor ${ }^{\mathrm{TM}}$ Metrics. Journal of Neuroscience 28, 11433-11434 (2008). https://doi.org/10.1523/ JNEUROSCI.0003-08.2008.

[21] Sakellaropoulou, R. Introducing open access options for Nature and the Nature research journals (2021). Online: https://www.springernature.com/gp/researchers/ the-source/blog/blogposts-open-research/openaccess-options-for-nature-and-the-natureresearch-journals/18782320. Springer Nature, For Researchers, Accessed: April, 2021.

[22] Gray, R. J. Sorry, we're open: Golden open-access and inequality in non-human biological sciences. Scientometrics 124, 1663-1675 (2020). https://doi.org/10.1007/s11192$020-03540-3$.

[23] Walters, W. H. Information Sources and Indicators for the Assessment of Journal Reputation and Impact. The Reference Librarian 57, 13-22 (2016). https://doi.org/10.1080/ 02763877.2015 .1088426$.

[24] Research4Life. Open access publishing: options for reduced or waived publication charges. Online: https: //extranet.who.int/hinari/en/oaapc_info.php. World Health Organization, Accessed: July, 2021.

[25] Powell, Andrea. Guest Post - APC Waiver Policies; A Job Half-done? (2021). Online: https://scholarlykitchen. sspnet.org/2021/04/19/guest-post-apc-waiverpolicies-a-job-half-done/. The Scholarly Kitchen, Accessed: July, 2021

[26] Smith, E. et al. Knowledge sharing in global health research - the impact, uptake and cost of open access to scholarly literature. Health Research Policy and Systems 15, 73 (2017). https: //doi.org/10.1186/s12961-017-0235-3.

[27] Open access agreements (2021). Online: https: //www.openaccess.cam.ac.uk/publishing-openaccess/open-access-agreements. Publishing Open Access, University of Cambridge, Accessed: April, 2021.

[28] Open access policies at MIT (2021). Online: https: //libraries.mit.edu/scholarly/mit-open-access/. Scholarly Publishing, MIT Libraries, Accessed: April, 2021.

[29] Open Access | Environmental Health Perspectives (2021). Online: https://ehp.niehs.nih.gov/about-ehp/openaccess. Environmental Health Perspectives, Accessed: April, 2021.

[30] Olden, K. EHP Moves to Open Access. Environmental Health Perspectives 112, A13-A14 (2004). https://doi.org/10. 1289/ehp.112-a13.

[31] About Wellcome Open Research | How It Works | Beyond A Research Journal (2021). Online: https: //wellcomeopenresearch.org/about. Wellcome Open Research, Accessed: July, 2021.

[32] About Gates Open Research | How It Works I Beyond A Research Journal (2021). Online: https: //gatesopenresearch.org/about. Gates Open Research, Accessed: July, 2021.

[33] MEDLINE PubMed Production Statistics (2020). Online: https://www.nlm.nih.gov/bsd/medline_pubmed_ production_stats.html. U.S. National Library of Medicine, Accessed: July, 2021.

[34] Sever, R., Eisen, M. \& Inglis, J. Plan U: Universal access to scientific and medical research via funder preprint mandates. PLoS Biology 17, e3000273 (2019). https://doi.org/10. 1371 / journal.pbio.3000273.

[35] arXiv Monthly Submissions (2021). Online: https://arxiv. org/stats/monthly_submissions. arXiv.org | stats | montly submission rates, Accessed: April, 2021.

[36] 2020 MEDLINE/PubMed Baseline (2020). Online: https://www.nlm.nih.gov/bsd/licensee/2020_ stats/2020_LO.html. National Library of Medicine, National Institutes of Health, Accessed: April, 2021.

[37] Salary Cap, Stipends, \& Training Funds (2021). Online: https://www.niaid.nih.gov/grants-contracts/ salary-cap-stipends. NIH: National Institute of Allergy and Infectious Diseases, Accessed: April, 2021.

[38] New Policy for Open Access and Publication Costs (2014) Online: https://www.fwf.ac.at/en/news-and-mediarelations/news/detail/nid/20141219-2097/. FWF Der Wissenschaftsfonds, Accessed: April, 2021.

[39] Open Access Policy (2021). Online: https: //wellcome.org/ grant-funding/guidance/open-access-guidance/ open-access-policy. Grant Funding | Wellcome, Accessed: April, 2021.

[40] McNutt, M. Opinion: "Plan S" falls short for society publishers-and for the researchers they serve. Proceedings of the National Academy of Sciences of the United States of America 116, 2400-2403 (2019). https://doi.org/10. $1073 /$ pnas.1900359116.

[41] Waltman, L., Larivière, V., Milojević, S. \& Sugimoto, C. R. Opening science: The rebirth of a scholarly journal. Quantitative Science Studies 1, 1-3 (2020). https : / doi .org/10.1162/ qsi_e_00025.

[42] Plan S[how me the money]: why academic-led initiatives represent a more equitable, less costly publishing future (2018). Online: https://blogs.lse.ac.uk/ impact ofsocialsciences/2018/10/24/plan-showme-the-money-why-academic-led-initiativesrepresent-a-more-equitable-less-costlypublishing-future/. Impact of Social Sciences, The London School of Economics and Polictal Science, Accessed: April, 2021.

[43] RØttingen, J.-A. \& Sweeney, D. Financing open-access publication after 2024. Nature 572, 586 (2019). https : / / doi. org/10.1038/d41586-019-02547-y.

[44] PLOS and the University of California announce open access publishing agreement (2020). Online: https: //theplosblog.plos.org/2020/02/plos-and-theuniversity-of-california-announce-open-accesspublishing-agreement/. The Official PLOS Blog, Public Library of Science, Accessed: February, 2021.

[45] Anderson, R. Six Questions (with Answers!) about UC's and Elsevier's New Transformative Deal (2021). Online: https://scholarlykitchen.sspnet.org/2021/03/ $25 /$ six-questions-with-answers-about-ucs-andelseviers-new-transformative-deal/. The Scholarly Kitchen, Accessed: April, 2021.

[46] Publishing, S. MIT Framework for Publisher Contracts. Online: https://libraries.mit.edu/scholarly/publishing/ framework/. MIT Libraries, Accessed: July, 2021.

[47] Grudniewicz, A. et al. Predatory journals: no definition, no defence. Nature 576, 210-212 (2019). Bandiera_abtest: a Cg_type: Comment Number: 7786 Publisher: Nature Publishing Group Subject_term: Research management, Publishing, https://doi.org/10.1038/d41586-019-03759-y. 